\section{Un deber de los obstetras}

Un grupo de estudio del Real Colegio de Obstetras y Ginecólogos del Reino Unido ha recomendado que los obstetras pregunten siempre a sus pacientes si han sido víctimas de violencia en el hogar. Hasta $20 \%$ de las embarazadas que asisten a clínicas prenatales pueden haber sido víctimas de grave abuso físico, emocional o sexual. El grupo de estudio recomendó asimismo que las enseñanzas sobre este fenómeno social formen parte de la educación de los jóvenes que entran en la carrera de obstetricia. Además, estos deben ser evaluados y calificados por la forma en que abordan ese tema tan delicado. Según el informe entregado por el grupo, que se titula Violence against women [La violencia contra la mujer], todas las mujeres embarazadas deben tener por lo menos una consulta privada con el obstetra principal que se va a encargar de su atención médica, sin que asista el compañero ni ningún otro familiar, para revelar información de naturaleza confidencial. Si bien en el Reino Unido hay poca información sobre este problema, en los Estados Unidos de América muchos estudios indican que la mujer corre un mayor riesgo de violencia doméstica durante el embarazo y el período posparto. En esas circunstancias, la violencia está dirigida principalmente al abdomen o al pecho de la mujer y entre sus consecuencias cabe mencionar un aumento en las tasas de aborto, nacimientos pretérmino, bajo peso al nacer, corioamnionitis, lesiones fetales (incluso fracturas óseas y heridas punzantes) y muerte fetal.

Un hecho irónico es que el manejo actual de los nacimientos - con el compañero presente en la clínica durante el trabajo de parto y la paciente en posesión de las notas obstétricas- ha reducido las oportunidades que antes tenían las mujeres maltratadas de revelar sus experiencias al personal médico. Además de las consultas privadas, el grupo recomendó que las unidades de maternidad lleven un juego de notas confidenciales distintas de las que tiene la paciente durante el parto. Se sugiere que los obstetras respeten la intimidad de sus pacientes y que soliciten su consentimiento antes de compartir con terceros cualquier información sobre violencia doméstica. Sin embargo, puede prescindirse de ese consentimiento cuando un profesional de salud sospecha que su paciente está en grave riesgo. En el segundo caso, la naturaleza de la reve- lación debe estar claramente documentada. Susan Bewley, directora de obstetricia de la asociación de hospitales St. Thomas y Guy de Londres y miembro del grupo de estudio ya mencionado, califica de horripilante la idea de que un hombre ataque a una mujer embarazada, pero señala que para el hombre la preñez constituye un período de cambio y estrés, con desvelos y pérdida de la atención de que antes gozaba. Añade que la violencia doméstica es un tema tabú que pocas personas abordan espontáneamente. (Abbasi K. Obstetricians must ask about domestic violence. BMJ 1988;316:9.)

\section{Patrones de mortalidad en la población hispana de los Estados Unidos}

En los Estados Unidos de América, las encuestas de mortalidad sirven para establecer prioridades de salud pública y entender los factores subyacentes que determinan los riesgos y problemas de salud de diferentes grupos étnicos. Dentro de los límites territoriales del país, la población hispana comprende 22,4 millones de personas y se está multiplicando a un ritmo cinco veces más rápido que cualquier otra minoría étnica. Para el año 2000 es probable que sea el grupo minoritario más grande del país. Sin embargo, no existe una buena descripción de la mortalidad entre los hispanos, pues las primeras estadísticas se recogieron después de 1980 y no fue hasta 1993 que se abarcaron todos los estados y el Distrito de Columbia. El Centro Nacional de Estadísticas de Salud (NCHS) ha estado recolectando datos mediante las encuestas semanales de muestras de población probabilísticas que realiza con su programa National Health Interview Survey (Encuesta Nacional de Entrevistas de Salud).

En un estudio reciente se evaluó el patrón de mortalidad de la población hispana utilizando datos obtenidos por el NCHS de 1986 a 1990 sobre una muestra representativa de 297640 personas de raza blanca no hispanas, 53552 de raza negra y 27239 de extracción hispana, de 18 años o más. Las defunciones se verificaron por confrontación con el índice nacional y la información en los certificados correspondientes se comparó con la obtenida en las entrevistas y se clasificó en cinco criterios de acuerdo con el número de detalles de identificación 
confirmados. El criterio 1 incluía apareamiento perfecto en cuanto al número de seguridad social, nombre y sexo, además del estado, mes y año de nacimiento. El criterio 2 comprendía apareamiento exacto de la seguridad social, pero sin que coincidieran algunos de los otros detalles. En el 3, no se conocía el número de seguridad social, pero ocho o más de los otros detalles coincidían. Apareando criterios diferentes se derivaron estimaciones levemente distintas del número de muertes por grupo étnico. Estas diferencias fueron cuantitativamente más importantes en los hispanos. La mortalidad general estandarizada por edad fue menor en los hispanos y mayor en los negros. También se observó una interacción notable entre la raza y la edad. La razón de hispanos a blancos fue de 1,33, 0,92 y 0,76 en hombres de 18 a 44, 45 a 64, y 65 años y más, respectivamente. Entre las mujeres de los mismos grupos de edad, la razón de hispanas a blancas fue de 1,22, 0,75 y 0,70, respectivamente. Tanto en los hispanos como en los individuos de raza negra, la tasa de mortalidad fue más baja en las personas de mayor edad y mucho más alta en las menores de 45 años.

Estos resultados indican que la mortalidad general es menor entre los hispanos que entre los blancos no hispanos, especialmente en el grupo de mayor edad. Aunque no se trató de explicar la razón, es posible que los hispanos no se vean tan afectados por la enfermedad coronaria y los distintos cánceres como la población blanca del país. Entre otros factores que podrían aducirse figuran una dieta más rica en frutas y legumbres que la típica dieta norteamericana y algunos fenómenos psicosociales protectores. Por otra parte, muchos hispanos vuelven a su país de origen antes de morir y por lo tanto no figurarían en los registros de mortalidad estadounidenses. Entre las personas más jóvenes y las de edad mediana, los hispanos mostraron tasas de mortalidad iguales o mayores que las de los blancos. (Liao Y, Cooper RS, Cao G, Durazo-Arvizu R, Kaufman JS, Luke A, et al. Mortality patterns among adult hispanics: findings from the NHIS, 1986 to 1990. Am J Public Health 1998;88:227-232.)

\section{El ácido xanturénico induce el desarrollo del paludismo en el mosquito}

Los gametocitos sexualmente maduros del parásito que produce el paludismo circulan en la sangre del huésped vertebrado, detenidos en el estadio $G_{0}$ del ciclo celular. Solamente segundos después de que el mosquito vector se alimenta con la sangre del huésped, los gametocitos se convierten en células germinativas masculinas y femeninas. A los 10 minutos de la gametogénesis, los gametocitos machos y hembras ya han escapado de los eritrocitos que los envuelven y el macho ha producido ocho microgametos flagelados en un proceso llamado exflagelación. In vitro, esa transformación requiere exposición simultánea a un mínimo de dos estímulos: el enfriamiento de la sangre ingerida a $5{ }^{\circ} \mathrm{C}$ menos que la del huésped vertebrado y un aumento del $\mathrm{pH}$ de 7,4 a entre 8,0 y 8,2 o la agregación de un factor activador termoestable de bajo peso molecular. In vivo, la sangre ingerida por el mosquito tiene un $\mathrm{pH}$ de 7,5 a 7,6 y se ha comprobado que el segundo factor inductor, componente endógeno del mosquito, es el ácido xanturénico. En combinación con el pH apropiado, este factor también puede inducir la gametogénesis in vitro.

La pesquisa que permitió descifrar la estructura molecular del factor misterioso comenzó con la preparación de extractos activos de pupas de Anopheles stephensi. Alrededor de 100 a 150 pupas se hirvieron y la extracción se hizo con cloroformometanol, seguida de ultrafiltración y purificación por cromatografía líquida de fase inversa. La actividad del factor se vigiló mediante un bioensayo de exflagelación in vitro con Plasmodium berghei. Se detectó un solo pico de actividad biológica correspondiente a un componente con actividad ultravioleta eluido a los 15,8 minutos. El análisis continuó con espectrometría de masa, electroforesis y elución con ácido acético. Poco a poco se descubrió que el factor desconocido era una sustancia ácida de carga negativa, posteriormente identificada como neutra y con una masa molecular de 205, por ser impar el número de átomos de hidrógeno. Estos datos se confrontaron con los de experimentos anteriores y se combinaron con estudios de derivación microquímica para determinar la estructura con más exactitud. A pesar de la escasez del factor purificado, se logró medir la masa del ion cuasimolecular mediante espectrometría de masa con bombardeo atómico y se encontró una composición atómica de $\mathrm{C}_{10} \mathrm{H}_{7} \mathrm{NO}_{4}$, correspondiente a una estructura aromática o pseudoaromática insaturada. Otras características apuntaron hacia el ácido xanturénico. En condiciones estándar de ensayo, a un $\mathrm{pH}$ de 7,4 , un ácido xanturénico sintético induce exflagelación en $P$. berghei. A pesar de su habilidad para iniciar la fase descrita del paludismo, el ácido xanturénico no es producto exclusivo de los mosquitos, sino que existe en el suero de mamíferos en pequeñas concentraciones. Esta identificación permite estudiar la regulación de la gametogénesis del paludismo en el nivel celular y quizá identificar los receptores parasitarios del ácido xanturénico y aclarar otros proce- 
sos. Puesto que la gametogénesis es el primer paso en la transmisión de parásitos por el mosquito, este descubrimiento puede llevar a la ideación de nuevos métodos para interrumpir la transmisión del paludismo con inhibidores químicos o antagonistas de la actividad del ácido, o tal vez a la selección de nuevos genotipos de mosquito resistentes a la infestación (Billker O, Lindo V, Panico M, Etienne AE, Paxton T, Dell A, et al. Identificacion of xanthurenic acid as the putative inducer of malaria development in the mosquito. Nature 1998;392:289-292.)

\section{¿Pueden erradicarse los VIH escondidos?}

A principios de marzo de 1998, un grupo de científicos se reunió en una comunidad de Massachusetts con el fin de proponer formas de erradicar el VIH de las personas infectadas. Hace solo 3 años, esa intención hubiera sido pura fantasía. Sin embargo, el éxito notable de la combinación de varios medicamentos anti-VIH (la llamada terapia antirretrovirica de gran actividad [TAGA]) ha alentado a los investigadores a pensar en eliminar los últimos rastros de virus del organismo y en la manera de hacerlo. Durante las discusiones, se destacó la inmensa dificultad de la tarea vislumbrada. El obstáculo principal es que, aun en personas cuya carga viral es indetectable, el virus se mantiene agazapado en diversas células. Se esconde, a salvo del alcance del sistema inmunitario y en de los medicamentos antivirales, dentro de células sanguíneas con infección "latente" en el cerebro, los ojos, los testículos, el timo, la espina dorsal y otros tejidos. Entre las estrategias discutidas figuraron la de inyectar al paciente con mensajeros del sistema inmunitario que desalojaran al virus, de tal modo que el propio sistema del paciente pudiera alcanzarlo, y la de buscar maneras de meter furtivamente los medicamentos más allá de las fronteras protectoras que le impiden entrada, como la barrera hematoencefálica. El escondite más vulnerable a los tratamientos actuales son las células sanguíneas con infección latente, que llevan el genoma viral entretejido en su propio genoma pero no producen copias activas del virus. Alguien propuso mantener a los pacientes en tratamiento con TAGA para controlar el virus hasta que mueran todas las células infectadas (macrófagos y linfocitos T). Se calcula que los macrófagos morirían primero y las células $\mathrm{T}$ a los 5 años o menos. Sin embargo, es mucho tiempo para ser tratado con TAGA, que requiere docenas de píldoras diarias y que tiene efectos secundarios graves. La supervivencia de los macrófagos puede ser mucho más larga, señalaron varios participantes. En el Instituto Scripps de La Jolla se ha encontrado que la infección por VIH alarga la vida de esas células en murinos. También se mencionó la presencia de macrófagos un año después de haberse iniciado la TAGA. Hubo también dudas sobre cómo respondería el sistema inmunitario una vez que la TAGA se suspendiera. ¿Terminaría de eliminar los pocos virus restantes?

Un tema muy debatido fue la posible vacunación con VIH para fortalecer el sistema inmunitario, puesto que la misma disminuye la diseminación de los virus, pero no puede impedirla. Sugirieron algunos investigadores que la erradicación en la sangre no es necesariamente el camino indicado y que es preferible procurar que sea el sistema inmunitario el que controle los virus por largos períodos. Se mencionó un tratamiento cíclico para fortalecerlo. No obstante, aunque se pudiera eliminar el virus de la sangre, es probable que pueda eliminarse por completo debido a su predilección por el sistema nervioso central. Un científico expresó inquietud por la presencia de un reservorio viral en el cerebro, pues no hay forma de medir con precisión la concentración del VIH en el tejido cerebral, donde estimula la producción de toxinas que causan demencia y está protegido por la barrera hematoencefálica. Este mecanismo impide la entrada de las células inmunitarias y de los medicamentos. Si estos consiguen llegar al cerebro, son una espada de doble filo, ya que penetran en cantidades ínfimas que solo provocan el desarrollo de resistencia en el virus. Se propuso aprender más sobre los sitios del organismo que ponen barreras similares efectuando necropsias en pacientes con VIH que mueren relativamente saludables en accidentes. También se sugirió crear un banco de tejidos de esos sitios. Esta reunión marcó una nueva fase en los esfuerzos por erradicar el VIH del organismo humano. (Cohen J. Exploring how to get at-and eradicate-hidden HIV. Science 1998;279: 1854-1855.)

\section{Cuatro temas de reforma en los sistemas de salud europeos}

En los años noventa, varios organismos internacionales han publicado estudios sobre el sector de la salud. El más reciente se fundamenta en una amplia encuesta patrocinada por la OMS con objeto de hacer un análisis comparado de los 51 Estados Miembros de la Región de Europa. Con ese fin se recogieron datos epidemiológicos, sociológicos, de comportamiento organizacional y gerencia, así como información sobre la economía y el financiamiento de los servicios de salud. En esta época en 
que los Estados Miembros de la OPS se han comprometido a reformar sus sistemas de salud, puede ser especialmente apropiado contemplar las experiencias de reforma habidas en Europa. En este caso, reforma se definió como un proceso intencionado, sostenido y sistemático de cambios estructurales en uno o más subsectores de salud. El período aludido comenzó a mediados de los años ochenta, cuando junto con presiones de índole demográfica, tecnológica y financiera en los sistemas de servicios de salud, surgió gran interés en servicios de mayor calidad, eficiencia y efectividad, y en que los pacientes tuvieran mayor influencia en el cuidado de su salud.

$\mathrm{El}$ artículo que presentamos se refiere principalmente a los países de Europa occidental, donde se observaron cuatro retos constantes para los encargados de tomar las decisiones atinentes a las políticas de salud: 1) la función cambiante del Estado y del mercado; 2) la descentralización; 3) los derechos del paciente; y 4) el papel que desempeña la salud pública. En cuanto al primero, no hay un concepto único de mercado que se relacione con los sistemas de atención de la salud. Los mecanismos de mercado abarcan instrumentos específicos, como la autonomía del paciente, los contratos negociados y la licitación abierta, que se introducen en los subsectores de asignación o distribución de fondos o de producción. Un gran número de países combinan elementos del mercado y del Estado, usando incentivos de estilo mercaderil mientras que las instalaciones y su operación siguen siendo propiedad y responsabilidad del sector público. Este abordaje híbrido se ha llamado mercado interno, competición pública y cuasimercado. Su diseño e implementación han tenido una repercusión importante en la reforma del sistema en España, Finlandia, Italia, el Reino Unido y Suecia, y en varios países del centro y oriente de la Comunidad Europea (CE) y de la Comunidad de Estados Independientes (CIS).

La descentralización surgió como respuesta a los defectos de las grandes instituciones públicas centralizadas, por ejemplo, la falta de eficiencia, de innovación y de sensibilidad a los intereses de los pacientes. No obstante, para que el Estado pueda delegar funciones a las autoridades regionales o municipales, es preciso contar con buena capacidad gerencial en el nivel local, claridad ideológica en la ejecución de tareas y receptividad para aceptar maneras diversas de interpretar un problema. En varios países, sobre todo en la Europa poscomunista, se ha hecho evidente que estos son requisitos indispensables para que la descentralización no redunde en consecuencias negativas, tales como fragmentación de los servicios, más inequidad, manipulación política por parte de intereses más poderosos y debilitamiento de las funciones regula- doras del sector público. La experiencia de esos países también indica que no da buenos resultados descentralizar el poder de decisión de ciertas áreas, por ejemplo, la estructura principal de la política de salud; las decisiones estratégicas con respecto al desarrollo de recursos de salud; la reglamentación de la seguridad pública; y el monitoreo, asesoramiento y análisis de la salud de la población y de la calidad de los servicios.

El tercer tema de la reforma europea es el gran deseo de los pacientes de decidir la selección de médicos y hospitales y de participar en la toma de decisiones sobre intervenciones médicas electivas. Los pacientes también insisten en participar en la toma de decisiones políticas de alcance local. Las naciones europeas varían mucho en cuanto a la latitud que tienen los pacientes en esos aspectos. La opción de hospital y especialista para procedimientos electivos sigue siendo controvertida y no hay ningún consenso internacional de si los pacientes deben autorremitirse al cuidado de especialistas o si los médicos generales deben continuar con la función de "porteros". En Alemania, Israel y algunos otros países, los suscritores pueden elegir sus compañías de seguro, pero en los Países Bajos la introducción de un poco de competición entre compañías de seguros impidió la solidaridad necesaria para desarrollar una fórmula de ajuste sensible de los pagos por capitación. En algunos países de la CE y de la CIS, los seguros competitivos han aumentado demasiado de precio en proporción a sus servicios. En Finlandia, Países Bajos y algunos otros países se han implantado mecanismos para proteger los derechos de los pacientes, no necesariamente con participación pública, pero teniendo en cuenta la responsabilidad de los proveedores hacia los pacientes y la confidencialidad de la información. La ley holandesa sobre el contrato médico trata la relación médico-paciente como un contrato especial de la ley civil. Un paciente tiene el derecho de demandar al médico y de hacer cumplir legalmente sus derechos, sin intervención del gobierno.

El cuarto tema se refiere a los esfuerzos por destacar la importancia de la salud pública en la elaboración de políticas de salud. Actualmente se observa en los países europeos orientales y occidentales una disparidad creciente en la esperanza de vida y la mortalidad, que debería influir en las reformas de la CE y la CIS. Además, en Europa occidental hay fuertes reacciones públicas con respecto a la promoción de la salud y la prevención de las enfermedades.

En la práctica, es limitado el impacto que tienen los servicios sanitarios en el estado de salud de una población. Los determinantes principales dependen de las políticas de los sectores de educa- 
ción, vivienda, empleo y agricultura. En reconocimiento de ello, los promotores de la salud pública y organizaciones como la OMS han luchado por aumentar la cooperación intersectorial en las decisiones sobre las futuras reformas de salud. Las reformas que conciernen a las cuatro áreas mencionadas permiten que la salud pública asuma nuevos papeles, incluso como participante en la compra del cuidado de la salud y en la puesta en marcha de mecanismos para evaluar la efectividad, eficiencia y calidad de los servicios de salud. (Saltman RB, Figueras J. Analyzing the evidence on European health care reforms. Health Affairs 1998;17:85-108.)

\section{Realización de los estudiantes de medicina mediante el servicio a la comunidad}

Parece haber consenso general en que hoy día los estudiantes de medicina están más interesados en la seguridad laboral y la buena vida de un especialista que en la dedicación y el compromiso moral que exige el ejercicio de su profesión en una clínica de barrio. Suele opinarse que pocos tienen la vocación de ayudar al prójimo, a pesar de que la situación está cambiando y de que ha habido un aumento reciente de los graduandos que optan por hacerse médicos generalistas. E. Eckenfels, del Departamento de Medicina Preventiva de la Universidad Rush en Chicago, sostiene que los que así piensan están equivocados y juzgan mal a los jóvenes de nuestra época. A su parecer, estos tienen que enfrentar un gran dilema suscitado por los tres "malestares" del mundo moderno, que son, específicamente, el exagerado énfasis en el individualismo, el razonamiento instrumental basado en la eficiencia burocrática y la pérdida de acción política.

La exageración del individualismo nos hace perder la imagen del yo como parte del mundo que nos rodea. En el mundo de la medicina, esta tendencia se expresa en la prestigiosa figura del médico académico, rodeado de una jerarquía que trasciende el campo de la medicina. Esta realización exclusivamente personal tiende a convertir a los pacientes, al personal auxiliar y al entorno profesional en instrumentos de la carrera del especialista. El razonamiento instrumentalista, por su parte, está dirigido a recalcar el paradigma de la organización moderna, que consiste en conseguir una máxima y eficiente producción basada por lo general en el análisis del costo-beneficio. En los hospitales el tratamiento médico a menudo se despersonaliza y se convierte en un asunto puramente técnico y ajeno al ser humano que lo recibe. Como consecuencia del individualismo y el razonamiento instrumentalista, el médico no funciona como agente social, a pesar de tener una licencia que le exige servir a la sociedad más que a sí mismo. No suele haber en esta profesión un activismo político por el bien de todos. Más bien, las asociaciones de médicos luchan por reformar las leyes sobre la mala práctica, controlar la competencia en el mercado o lograr otras formas de proteccionismo económico. Se otorga mayor peso a la oferta que a la demanda y el hospital y los médicos tratan de imponer a los pacientes su tecnología y conocimientos en vez de discernir lo que necesitan el paciente y la comunidad. Esto, por supuesto, es lo que comunica la enseñanza en muchas escuelas de medicina, que rara vez aborda los problemas existenciales que el médico encara a diario.

En 1992 J. M. Colwill marcó un hito con la publicación de su artículo "Where have all the primary care applicants gone?" (N Engl J Med 1992;362: 387-409), en que lamenta la escasez de estudiantes que aspiran a dedicarse a la medicina general. Desde entonces se han propagado en los Estados Unidos tres programas sociales: The Health of the Public (HOP), el aprendizaje en el servicio promovido por Health Professions Schools in Service to the Nation y el Community-Campus Partnerships for Health, de creación reciente. La Universidad Rush sintetiza los fines de los tres programas anteriores con los del suyo, Rush Community Services Initiative. En estos programas, los estudiantes de medicina trabajan voluntariamente en equipos supervisados por profesores para identificar a individuos, grupos y hogares en alto riesgo. De esa forma se aproximan a las causas sociales y ambientales de las enfermedades. El deseo de participar en este aprendizaje en el servicio fue manifestado por los propios estudiantes en reuniones de la Asociación de Estudiantes de Medicina. El HOP ya se ha extendido a 33 centros académicos, lo cual ilustra la popularidad y aceptación de estos programas, tanto por el público como por los estudiantes. Se celebran discusiones con estudiantes de diversas edades sobre prevención; educación sexual; atención pediátrica y del escolar pequeño; cuidado de personas pobres sin seguro de enfermedad; servicios a grupos étnicos de inmigrantes; presentaciones en escuelas, centros comunitarios y otras organizaciones; ayuda a las personas de mayor edad, y muchas otras actividades. Estas experiencias en el arte de la atención primaria están afectando profundamente a los futuros médicos. Su trabajo con grupos de personas pobres y de inmigrantes es una forma de activismo social y los ayuda a respetar y entender otras culturas y a reflexionar sobre las injusticias que observan en la sociedad. Esta inmersión en un espacio de aprendizaje existencial nutre sus valores de solidaridad humana. El profesor Eckenfels atestigua que 
los estudiantes sufren un profundo cambio cuando participan en estos programas. Aprenden a ver el mundo de forma diferente y asumen profundos compromisos personales que satisfacen su necesidad de hacer "algo de valor". Cuando se le preguntan sus recomendaciones al respecto, este médico docente contesta que las escuelas de medicina son bien conocidas por su resistencia al cambio y que no es factible ni deseable establecer programas obligatorios de esta naturaleza, ya que ello los despojaría de su mayor ventaja e importancia: el hecho de haber nacido voluntariamente de los estudiantes. (Eckenfels EJ. Contemporary medical students' quest for self-fulfillment through community service. Acad Med 1997;72:1043-1050.)

\section{Medicamentos costo-efectivos para prevenir las infecciones oportunistas del sida}

En los programas de asistencia sanitaria los recursos suelen ser limitados y es importante que tanto los clínicos como los pacientes obtengan el máximo beneficio por el menor costo. Hoy día hay muchas opciones profilácticas contra las enfermedades oportunistas relacionadas con el sida, pero las diferencias en las tasas de incidencia, así como en la eficacia, toxicidad y costo de los medicamentos, crean incertidumbre a la hora de tomar decisiones. Armados con datos obtenidos de varios estudios extensos, siete investigadores del Centro Médico y de la Escuela de Medicina de la Universidad de Boston, Massachusetts, trataron de determinar el costo-eficacia de antibióticos solos y en combinación para prevenir enfermedades oportunistas en pacientes de sida. Freedberg et al. elaboraron un modelo Markov de simulación con el fin de comparar las diferentes estrategias de profilaxis contra la neumonía por Pneumocystis carinii (NPC), la toxoplasmosis, infecciones micóticas e infecciones por el complejo Mycobacterium avium (CMA) y por citomegalovirus (CMV) en pacientes con VIH. En el estu- dio se proyectaron la esperanza de vida, la esperanza de vida ajustada según la calidad, los costos médicos directos durante todo el ciclo vital, y el costo-eficacia en dólares estadounidenses (US\$) por cada año de vida ajustado según la calidad (AVAC) que se hubiera ganado.

Para los pacientes con recuentos de células CD4 de 200 a 300/ $\mu \mathrm{L}$ y que no reciben profilaxis se proyectó una esperanza de vida ajustada según la calidad de 39,08 meses y un costo promedio durante todo el ciclo vital de US\$ 40288 . La profilaxis con trimetoprima-sulfametoxazol contra la NPC y la toxoplasmosis en pacientes con recuentos de células CD4 de 200/ $\mu \mathrm{L}$ o menos aumentó la esperanza de vida ajustada según la calidad a 42,56 meses, lo que incrementó el costo US\$16000 por cada AVAC ganado. En pacientes con CMA y recuentos de células CD4 de menos de 50/ $\mu \mathrm{L}$, las ganancias fueron menores en cuanto a la esperanza de vida. El grupo descubrió que el costo-eficacia de la profilaxis contra las infecciones oportunistas varía mucho, pero el mayor valor relativo se obtiene previniendo la NPC o la toxoplasmosis y el CMA. Los antibióticos, solos o en combinación, en orden de mayor a menor costo-efectividad fueron 1) trimetoprima-sulfametoxazol para prevenir la NPC y la toxoplasmosis, US\$16000 por cada AVAC ganado; 2) azitromicina para prevenir el CMA, US\$35000 por AVAC ganado; 3) fluconazol para prevenir las infecciones micóticas, US\$100000 por AVAC ganado, y 4) ganciclovir para prevenir el CMV, US $\$ 314000$ por AVAC ganado. El orden se mantuvo aun cuando se usaron diferentes supuestos sobre la causa de muerte, calidad de vida, incidencia de infección, costo de los antibióticos y estado de salud. Según el estudio, las combinaciones más costo-efectivas son la trimetoprima-sulfametoxazol con azitromicina o la trimetoprima-sulfametoxazol con azitromicina y fluconazol. (Freedberg KA, Scharfstein JA, Seage III JR, Losina E, Weinstein $\mathrm{MC}$, Craven DE, et al. The cost-effectiveness of preventing AIDS-related opportunistic infections. JAMA 1998;279:130-136.) 